news fezture

Across the developing world, people are dying after being peddled fake pharmaceuticals. Peter Aldhous reports from southeast Asia, where scientists, doctors and regulators battle against organized crime.

S am Veasna's loss is still keenly felt in Cambodia, five years after his untimely death. In a desperately poor country where most people are preoccupied with the daily struggle for survival, he was a tenacious field biologist and passionate advocate for conservation whose work made a real difference - until he fell prey to malaria.

In November 1999, Veasna ventured to the remote north of the country in search of the elusive kouprey - a wild cow that is Cambodia's national animal, but which may already be extinct. True to form, the kouprey evaded Veasna. But the mosquitoes didn't. Back home in Siem Reap, where he ran the provincial government's wildlife office, Veasna fell ill. He was treated with tablets labelled as mefloquine, an antimalarial drug, which should have restored him to health. But his fever continued to rage.

"By the time we realized what was going on, he was slipping into a coma," recalls Colin Poole, who heads the Asia programme of the
Wildlife Conservation Society, based in New York. "We organized a medical evacuation to Bangkok." But it was too late. Veasna was pronounced dead on 3 December, shortly before the plane that was to whisk him to Thailand touched down in Siem Reap. He was just 33, and left behind a wife and three children.

Veasna was almost certainly a victim of the trade in counterfeit drugs - bogus products that often contain no active ingredients, or the wrong ones. Cambodia can ill afford to see its brightest lights snuffed out in this way, having already lost a generation of intellectuals in the 1970s to the genocidal Khmer Rouge regime. Yet a criminal investigation into Veasna's death soon collapsed through lack of evidence - the offending tablets had been thrown away. If he hadn't been internationally renowned, things would probably never even have got that far. Many ordinary Cambodians are thought to suffer a similar fate each year, their deaths gaining scant media attention and prompting no official response.

\section{Hologram wars}

In his office at the Hospital for Tropical Diseases in Ho Chi Minh City, Vietnam, Jeremy Farrar tosses me two blister packs of tablets on which the name 'Guilin Pharma' is printed in blue. The company's factory in Guangxi province, southern China, is the leading source of artesunate, a highly effective treatment against malaria.

One of the packs doesn't look quite right. The printing seems slightly washed out. And, tellingly, its security sticker is revealed on close scrutiny not to be a hologram, but a piece of shiny foil with a printed pattern. After examining the two, l'd be fairly confident of spotting the fake if I was offered it over a pharmacy counter.

Unfortunately, the fake artesunate circulating throughout southeast Asia today is much harder to detect. Paul Newton, who is studying the problem of counterfeit drugs in the region from 
No one knows how many deaths in the developing world can be blamed on fake pharmaceuticals. But thanks to the diligence of researchers who are monitoring the effectiveness of malaria treatments, we now do know that the trade in counterfeit antimalarial drugs is rife across southeast Asia. Scientists are battling the menace of fake drugs by raising awareness among doctors and their patients, and running lab tests to screen for counterfeits. But there's only so much they can do. Next week in Paris, at the 2nd Global Forum on Pharmaceutical Anticounterfeiting, experts will try to plot the way forward. It's already clear that this will require more rigorous efforts to crack down on the ruthless criminals who profit from the trade in bogus drugs.

\section{Innocent victims}

The alarm about fake antimalarials began to sound just months before Veasna's death. In 1999, Jan Rozendaal, who then ran the European Union's Cambodia Malaria Control Project, began to hear reports of patients who failed to respond to treatment with artesunate. This drug, derived from a Chinese herb, is highly effective against forms of the malaria parasite that resist earlier generations of antimalarials - particularly when used in combination with mefloquine. So if the parasite was evolving resistance to artesunate, it would have been a major blow.

But the problem wasn't drug resistance. Those who failed to respond to artesunate had bought suspiciously cheap supplies from small commercial pharmacies. So Rozendaal collected his own samples from similar outlets, and sent them for analysis to the Thai Ministry of Public Health ${ }^{1}$. The drugs were sold in blister packs bearing the name of Guilin Pharma, a company in China's Guangxi province. But about half the packs contained dummy pills with no active ingredient. Close inspection revealed subtle differences in the packaging that distinguished them from the genuine Guilin product. It was a similar story for bottles of mefloquine tablets, purportedly manufactured in Australia. In this case, the fakes had carved out a dominant market share.

Disturbed by his findings, Rozendaal contacted Nick White, a leading malaria researcher at the UK Wellcome Trust's unit at Mahidol University in Bangkok. The trust has units and collaborators across southeast Asia, so White was able to extend Rozendaal's investigation to cover the entire region. Over a year, ending in August 2000, volunteers purchased artesunate in Cambodia, Laos, Myanmar, Thailand and Vietnam. Of a total of 104 samples bought more or less at random, $38 \%$ were found to be fakes containing no active ingredient $t^{2}$.

The researchers hoped their survey would raise awareness of the problem, and they subsequently called for international action to clamp down on the counterfeiters ${ }^{3}$. But a follow-up study, which concluded in February 2003 , revealed that the situation had actually worsened. This time, $53 \%$ of 188 artesunate samples were useless fakes ${ }^{4}$. Worse, the counterfeiters had upped their game, improving their mimicry of the Guilin packaging to the point that the fake packs were virtually indistinguishable (see'Hologram wars', below).

Back in 2000, many pharmacists probably knew they were selling knock-offs, says Arjen Dondorp, a clinician at the Wellcome Trust's Bangkok unit, who coordinated the second survey. “They'd say: 'This is a little bit less effective, but it's cheaper." In Cambodia, where the average annual income is about US\$300 and a course of artesunate sells for about US $\$ 1.50$, that was an especially compelling sales pitch. Today, Dondorp suspects that some pharmacists are being duped as well, and the price difference between genuine and fake artesunate has all but disap-
y organized crime, and peared. "It's clearly organized crime, and
highly sophisticated," says Dondorp. Sophisticated, maybe, but callous in the extreme. "You can think of it as attempted murder," he adds.

\section{Streetlife}

In December, I visit the Cambodian capital, Phnom Penh, to get a feel for the environment in which this trade flourishes. There are many reminders that this is one of Asia's poorest countries: at one junction, people are picking through piles of garbage for anything that might be reused. I wander the streets, searching out the city's small pharmacies. Most consist of a single openfronted room, separated from the street by a simple counter. Packages of drugs line the walls inside. At each, I turn up with a scrap of paper on which I've written "artesunate or mefloquine" or "tetracycline". The last of these drugs is an antibiotic deployed against a variety of bacterial infections; it is also used, together with quinine, to treat malaria.

For someone used to the controlled
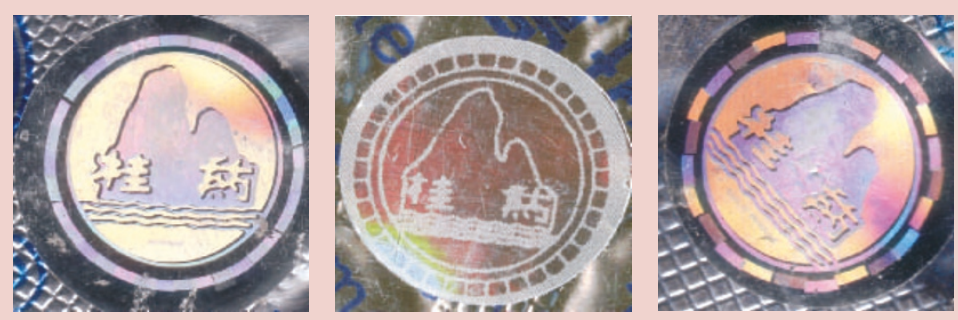

Copycats: (from left) the hologram on a genuine pack of Guilin Pharma drugs, a silver foil copy, and a convincing fake.

his base at the Mahosot Hospital in Vientiane, Laos, has documented seven distinct types of fake 'Guilin' artesunate. The counterfeiters soon began to incorporate security stickers bearing a real hologram, albeit a crude example. And the holographic stickers on the latest fakes, if anything, look more professional than the genuine version. Only an expert could reliably tell the two apart.

Yet it doesn't have to be that way, according to David Pizzanelli, sales and marketing manager with Light Impressions, a holography firm in Leatherhead, near London. "The main problem is that the genuine hologram is terrible," he says. Depicting the limestone hills that surround the city of Guilin, plus a few Chinese characters, it has little three-dimensional relief. A passable imitation could be knocked up by more than 200 workshops worldwide, says Pizzanelli. And at less than 15 millimetres across, the sticker is way too small. Surveys for credit-card companies have shown that security holograms need to be at least twice this size if people are not to be fooled by crude imitations.

The answer, argues Pizzanelli, is to incorporate a more complex, repeating hologram into the foil of the blister pack itself. There are fewer than a dozen companies worldwide who could supply such a security feature, making life extremely difficult for the counterfeiters. But this could require an investment running to millions of dollars. And without clear evidence of how much revenue is lost as a result of counterfeiting, it's hard for cautious drug-company executives to justify spending such sums.

Lucy Jiang, who is responsible for international affairs at Guilin, says the company is talking to the World Health Organization and other experts about ways to protect its product from counterfeiting. But it has no plans to introduce a much more sophisticated hologram. "The cost is so high that we cannot bear it," says Jiang. P.A. 


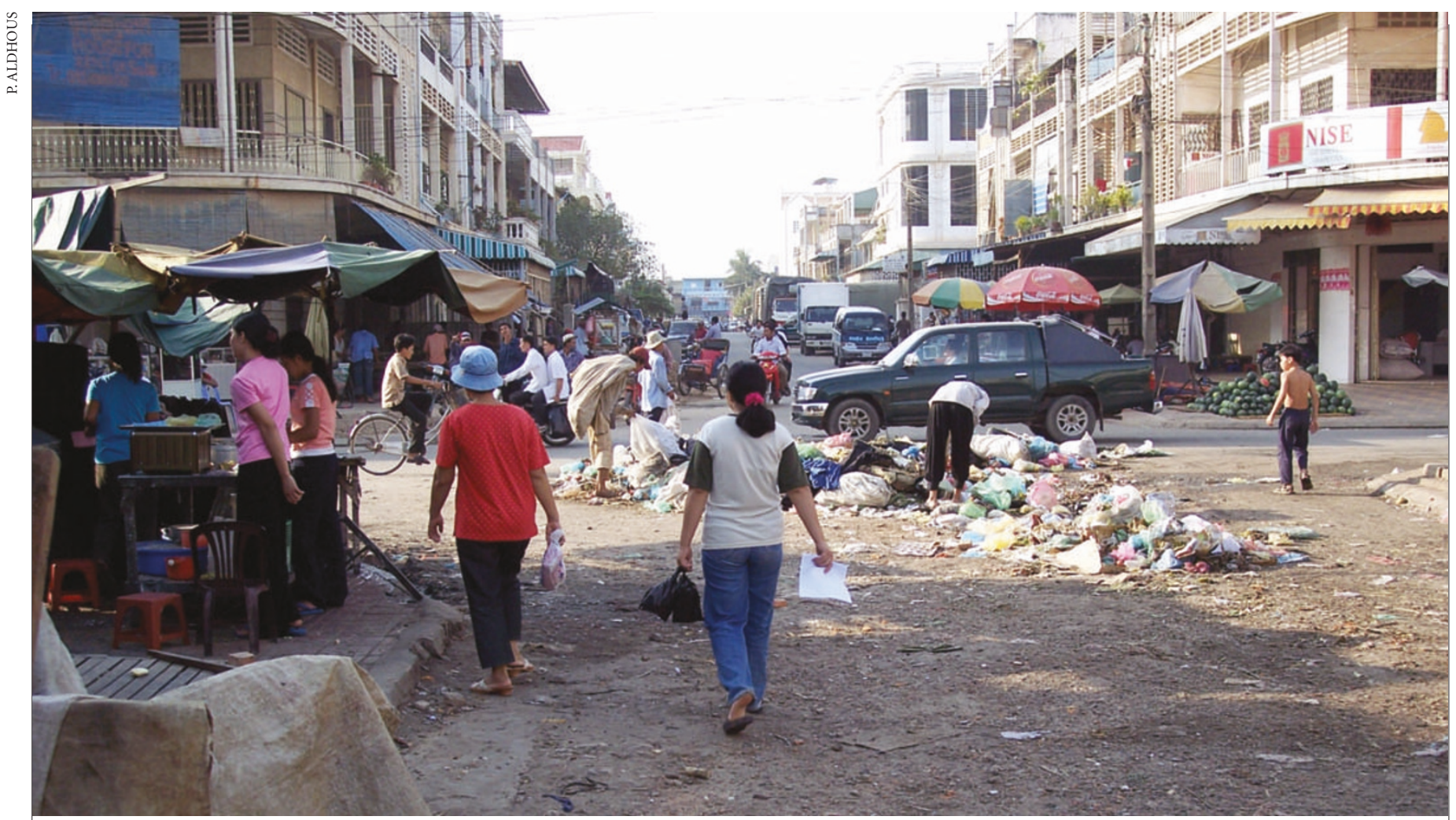

Mean streets: the impoverished population of Phnom Penh makes an easy target for criminals selling fake pharmaceuticals.

environment of a typical Western pharmacy, this shopping trip is an eye-opening experience. Over two days, I visit a total of 27 outlets. Only once am I asked about the condition the drugs are supposed to treat. "It's for a friend with a fever," I say, before enquiring about the dose. The pharmacist says that my friend should take three tablets of tetracycline each day. But for how long? She scrutinizes the Khmer language information sheet supplied with the antibiotic, which doesn't seem to help. "As long as you like," she eventually suggests - vague advice that could place patients at risk, and promote the spread of drug resistance.

\section{Faking it}

As I pocket the packages, I contemplate the odds of them being genuine. Two official surveys conducted by the Cambodian Ministry of Health, with the backing of the World Health Organization, have shed some light on this question. National drug-testing labs in Phnom Penh and Bangkok looked at 230 samples of 24 pharmaceuticals purchased on the Cambodian market in 2000, including antibiotics and painkillers. They found about $3.5 \%$ of them contained less than $60 \%$ of the labelled quantity of active ingredient ${ }^{5}$. When the survey was repeated for a wider range of drugs purchased in $2003,11 \%$ of the samples fell into this category $^{6}$. Both surveys also turned up a small number of products that contained the wrong ingredient.

Some of these problems may represent shoddy manufacturing, rather than conscious criminality. But ominously, the team that ran the second survey was unable to find any official record of the existence of five of the companies whose drugs they found on sale in Cambodia. 'Brainy Pharmaceutical', for instance, is supposedly based in Thailand, but is not registered with the appropriate authority in Bangkok. Its tested products included fake antibiotics with no active ingredients.

Chroeng Sokhan, vice-director of the Cambodian health ministry's Department of Drugs and Food, is trying to prevent bogus manufacturers from operating quite so brazenly in his country. His department, based in a run-down building in a shabby side street of Phnom Penh, has held workshops to educate retailers, and distributed posters warning of the dangers posed by counterfeit drugs — including some with photographs of known fakes. "Those products are harder to find on the market now," says Sokhan. In recent weeks, the anti-counterfeiting campaign has extended to broadcasting adverts on staterun television.

These activities have relied This 'minilab' allows users to check whether drugs are genuine. heavily on foreign aid, as do most efforts to combat drug counterfeiting in Cambodia. The US Pharmacopeia, a non-governmental body that develops standards to ensure drug quality, is working in the country with funding from the US Agency for International Development. Focusing on malaria drugs, it has already turned up samples of Brainybranded quinine that - like the bogus company's antibiotics - don't contain any of the correct active ingredient.

Part of the strategy has been to involve provincial officials in testing drug samples, so that they take ownership of the problem. "They were very surprised when they found fake drugs in their provinces," says Lon Chantap, a researcher at the National Center for Parasitology, Entomology and Malaria Control in Phnom Penh, who works on the project.

Testing the quality of drugs is usually the preserve of large, wellfunded national laboratories. But the US Pharmacopeia's project is also using a 'minilab' developed by the German Pharma Health Fund, a charity financed by that country's drug industry.

This portable kit allows local technicians to analyse pharmaceutical ingredients using simplified versions of 
techniques such as chromatography ${ }^{7}$. At the US Centers for Disease Control and Prevention in Atlanta, Georgia, analytical chemist Michael Green is similarly working on cheap drug-testing methods, including a red dye that turns yellow in the presence of artesunate $^{8}$.

But in Cambodia, problems thrown up by grinding poverty run deeper than the ability to afford good drug-quality tests. Qualified staff are few in number and poorly paid. Sokhan can call upon just 13 national inspectors to police the country's entire drug supply. As the sun sets, he takes me for a drive through the streets that surround Phnom Penh's Olympic Market, which are packed with small pharmacies and wholesalers that sell drugs on to retailers in the provinces. Many, says Sokhan, are unlicensed outlets, and their continued existence is obviously a major source of frustration for him. "Unbelievable," Sokhan mutters, as we turn back towards the main road.

The next morning I continue my shopping trip. My final haul consists of five blister packs of Guilin-branded artesunate, some loose capsules of mefloquine, and five samples of tetracycline. In addition, I have

three packets of a product called Malarine, which includes both artesunate and mefloquine pills and is distributed by Population Services International. This nonprofit body in Washington DC tackles problems with health and family planning in the developing world by placing affordable products into the commercial sector. At least these should be OK, I muse, before sending the samples to Green for testing.

\section{Clean sweep}

All of my drugs turn out to contain roughly the right quantities of active ingredients, and so seem to be genuine. Given that some of the pharmacies I visited carried Sokhan's posters, perhaps the campaign is having some effect. But Sokhan and other experts warn against reading too much into these results. As a wealthy Westerner, my sources suggest, I am more likely to be sold genuine drugs than a typical Cambodian customer. Perhaps if Veasna had been one of the many tourists who flock to Siem Reap to visit the ancient temples of Angkor, he would still be alive today.

For anyone familiar with Western practices of drug regulation, the solutions to Cambodia's problems with fake drugs seem clear: get police and customs officials to crack down on the distribution chain, allow only licensed pharmacists to continue operating, and close

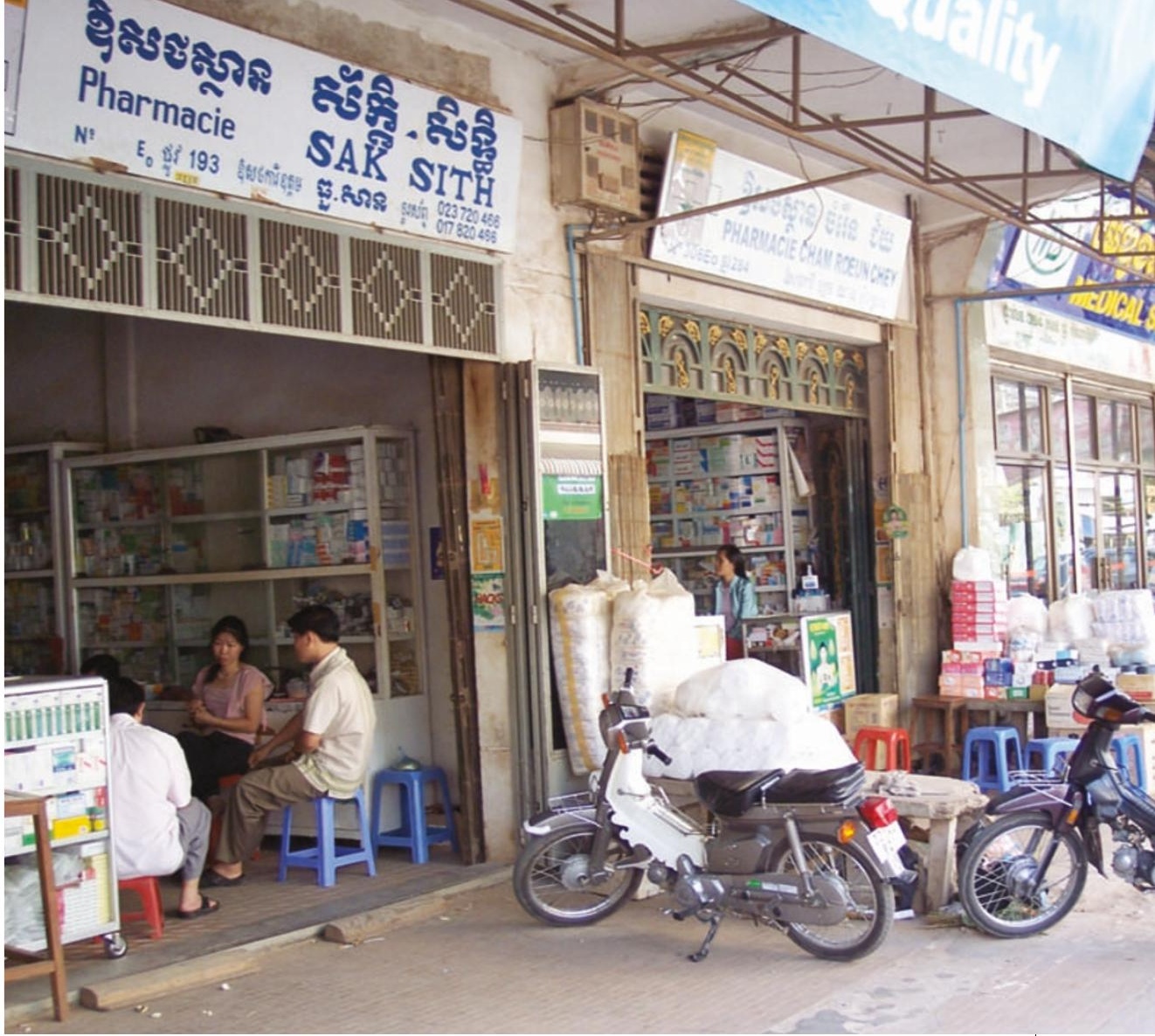

Life or death? A selection of drugs (below) bought from street pharmacies in Phnom Penh.

any pharmacy caught selling counterfeit products. But Sokhan says that his department doesn't have the power to enforce such measures. "We can do things only step by step," he says. "It's not easy." Sokhan

won't be pressed into further explanation, but Rozendaal is frank about the obstacles to progress. Corruption is endemic in Cambodia, he says, and the distributors of counterfeit drugs are protected by powerful figures in the government. Now working as a consultant in Indonesia, Rozendaal is free to speak out. But when he raised the alarm about fake drugs in Cambodia while running the European Union's malaria project, Rozendaal felt his job was threatened as spurious complaints about his competency reached his bosses in Brussels. For local officials, the stakes could be even higher. "You really take a big personal risk," says Rozendaal.

In some neighbouring countries, law enforcement is more rigorous. In Laos, for example, some pharmacies have been closed down. And as an example of what's possible, experts point to Nigeria, where one influential woman has made a courageous and effective stand against pharmaceutical counterfeiting (see 'In the line of fire', page 134).
But counterfeit drugs will continue to plague southeast Asia until the problem is defeated at its source. That means targeting the factories that are producing the fakes, which are mostly thought to be in China. This, in turn, will require pharmaceutical firms and governments to exert pressure on the Chinese authorities. Some progress is being made, says Joe Damond, deputy vicepresident for international affairs with PhRMA, the trade body that represents the US drug industry. Regulations designed to combat drug counterfeiting have recently been strengthened, he says.

The acid test will be how these are implemented. So far, Chinese drug counterfeiters have mostly been handed modest fines that they can write off as a cost of doing business. As a result, some organized criminals are believed to have shifted their activities from narcotics, where sentences are severe and include the death penalty, to fake pharmaceuticals. Those who mourn Veasna's death can confirm that this new trade is equally murderous. And they are still waiting for his killers to be brought to justice.

Peter Aldhous is Nature's chief news \& features editor.

Rozendaal, J. A. Lancet 357, 890 (2001)

. Newton, P. et al. Lancet 357, 1948-1950 (2001)

. Newton, P. N., White, N. J., Rozendaal, J. A. \& Green, M. D. Br. Med. J. 324, 800-801 (2002).

4. Dondorp, A. M. et al. Trop. Med. Int. Health 9, 1241-1246 (2004)

5t Study Report on Counterfeit and Substandard Drugs in Cambodia (Cambodian Ministry of Health, Phnom Penh, 2001).

. Second Study Report on Counterfeit and Substandard Drugs in Cambodia (Cambodian Ministry of Health, Phnom Penh, 2004). Jähnke, R. W. O. Pharm. Ind. 66, 1187-1193 (2004).

8. Green, M. D., Mount, D. L., Wirtz, R. A. \& White, N. J. J. Pharm. Biomed. Anal. 24, 65-70 (2000). 